DOI https://doi.org/10.18551/rjoas.2018-09.22

\title{
THE INFLUENCE OF PSYCHOLOGICAL EMPOWERMENT ON THE WORK EXHAUSTION AND EMOTIONAL INTELLIGENCE
}

\author{
Musadieq Mochammad Al \\ Faculty of Administrative Science, University of Brawijaya, Indonesia \\ E-mail: musadieqfia@ub.ac.id
}

\begin{abstract}
This research aims to determine the effect of psychological empowerment on the work exhaustion and emotional intelligence on the tour guide in Nusa Tenggara Barat Province, one of the provinces with the highest tourism income in Indonesia. The type of this research is explanatory research with a sample of 150 tour guides, taken from 653 people using stratified proportionate random sampling technique. The data analysis uses two analyses, namely descriptive with the help of SPSS version 20.0 and inferential analysis with Generalized Structured Component Analysis (GSCA). The result of this research shows that there is a negative significant influence between psychological empowerment on the work exhaustion. There is a positive significant influence between psychological empowerment on the emotional intelligence, and there is no significant and negative influence between work exhaustion on the emotional intelligence.
\end{abstract}

\section{KEY WORDS}

Psychological empowerment, work, exhaustion, emotional intelligence; tour guides.

Nusa Tenggara Barat (NTB) Province of Indonesia is one of the strategic tourism destinations. It is usually called as golden triangle of tourist destination in which Bali represents the West region, Sulawesi with Tanah Toraja represents the North region and Komodo Island represents the East region. NTB province has its own advantage, seeing the NTB's position which is adjacent to Bali because it is considered as the tourism paradise for foreign or domestic visitors. This, in turn, will be very beneficial to the NTB. The provincial government of NTB places tourism as the second priority after agricultural sector in a broad sense and establishes 15 potential areas that can be developed as the tourism area, nine in the Lombok Island, and six in the NTB province. The natural beauty and charm of the tourism in NTB will be more interesting by enhancing the soul of tourism because the hospitality played by the tourist guides becomes one of the strong reason for the tourist to visit NTB.

The tourist guide is a profession that is closely related to tourism, it has an important role in realizing the success of the regional tourism program. The reason is that tourist guide becomes the spread head that is directly opposite with the tourist or guest. The passion for tourist guide phenomenon in NTB in the training of tourist guide competence and to obtain the license since 2012 is higher compared to the previous year. The tourist guide in 2011 amounted to 220 people and almost $50 \%$ have not attended the standard training of the tourist guide and most of them have not obtained the official permit as tour guide from the authorized agency ("Hampir 50 Persen", 2012). In 2014, there are many tourist guides who have attended the standard training of tourist guide and there were about 563 people who have obtained a license to be a tourist guide. This shows that his or her work as tourist guide is intrinsic motivational that can reduce the sense of incompetence and strong self-control that allow the tourist guide to be able to survive and behave in line with their profession. Spreitzer (1995) refers to it as the psychological empowerment. The survey study related to psychological empowerment has also been conducted by Kong, Cheung \& Baum (2009) where the result published by Journal of China Tourism Research. The research identifies the profile of tourist guide's skills in order to face the rapid development of tourism in China. This result of the research concludes that education and standard training factors need to improve as these two factors give the contribution to enriching the knowledge and skills of the tourist guide to serve the guest with a high quality of service. 
The Head of Regional Representative Council (DPD) of the Indonesian Tour Guide Association (HPI) of NTB province and Association of Indonesian Tours and Travel Agencies (ASITA) of NTB province conclude that although there is a significant improvement in the tour guide's awareness to attend standard training of tourist guide competence and licence ownership, but the comparison between the tourists visit and the existence of tour guide is not equal. On the one hand, this is caused by the number of tourists visiting the NTB province which keeps increasing every year. On the other hand, the number of tourist guides who serve the tourist is not increased. The number of foreign tourists who visit NTB province in 2014 amounted to 69,881 people (BPS, 2015). But the number of tourist guides who serve these foreign tourists in NTB province was only 653 people (BPD HPI NTB, 2014). The gap will be more visible during high season. This can trigger low-quality service given by the tourist guides due to lack of human resources, affecting the occurrence of overwork and ultimately can trigger the occurrence of work exhaustion (Perewe, et al. 2002).

In addition, it can also affect the emotional intelligence of the tour guide. Considering that the tour guide is required to be able to master and manage himself in carrying out the tour as well as possessing the ability to build a good relationship with other people (Meyer, et al. 2004). Daniel Goleman called this ability as emotional intelligence. Goleman (2000) through his research state that emotional intelligence accounts for $80 \%$ of the determining factor for someone's successful life, meanwhile the other $20 \%$ is determined by IQ (Intelligence Quotient).

Spreitzer (1995) states that the psychological empowerment is the way people look at themselves in the working environment and the degree to which they feel capable of forming the job role. Conger \& Kaungo (1988); Thomas \& Velthouse (1990); and Spreitzer (1995) state that psychological empowerment can be understood as the multi construction consisting of: (1) Significance (the compatibility between the demand of a work role and someone belief, value, and behavior), (2) Competence (someone's belief of her or his own ability to do something specific in the work or the belief of his or her own ability to do the work creatively), (3) Self-determination (the belief that she or he has the chance to choose in order to start and manage the action), and (4) Impact (the extent to which a person can affect the outcome generated from his or her work). Meanwhile, Schaufeli, Maslach \& Marek (1993) argue that empowerment is related to the workload, the excessive workload can be one of the factors from a work which in the end affect the occurrence of work exhaustion. In addition, Jenskins (1996) argues that the importance of empowerment enables people to do things they previously could not do, including the ability in recognizing self-emotion, managing self-emotion, motivating oneself, recognizing the emotion of other people, and the ability to be able to foster the influence with others. Goleman (2000) calls it as emotional intelligence.

Several studies have been conducted on the psychological empowerment, especially in developed countries in America and Asia (Chow, et al. 2005; Tutar, Altinoz \& Altinoz, 2010; Sarwar \& Khalid, 2011; dan Meyerson \& Dewettinck 2012). The construct that has been developed by the researchers show the improvement and strengthen the theoretical concept from Thomas \& Velthouse (1990); and Spreitzer (1995). Survey research on the effect of empowerment and work exhaustion previously done by some researchers such as Yagil (2006) who found that the overall empowerment construct has significant negative impact on the work exhaustion including emotional exhaustion, depersonalization, and the declining of personal performance. On the other hand, Greco, et al. (2006) show that the overall construct in the empowerment has significant positive effect on the work exhaustion. Alam (2010) has conducted a hypothesis test in which the result shows that construct in the empowerment has no significant influence on the work exhaustion. However, Alam (2010) has conducted preposition test of the effect of psychological empowerment on the emotional intelligence, where it is successfully proven that psychological empowerment has significant positive influence on the emotional intelligence. Thomas, et al. (2012) proposes a positive and significant influence between emotional exhaustion and emotional intelligence. Furthermore, there is also significant positive influence between depersonalization and emotional intelligence. There is also a significant positive influence on the personal 
achievement and emotional intelligence. Based on that, Thomas, et al. (2012) concludes that work exhaustion has significant positive influence on the emotional intelligence.

It is important to conduct this research because the competitiveness of human resources will be able to affect the quality of the service and the main component of tourism lies in the quality of service. This has been proven by Vucetic (2012) in a field research by using 30 travel agents as samples taken from 54 population of travel agents in Montenegro, concluding that the quality of a service given by the human resources determines by the competitive advantage present within the human resources itself. The competitive advantage of tour guide can be determined from their belief to carry out a guiding task reflected from the psychological empowerment which is a reflection of the empowerment where the perception focus lies within oneself and most felt by the tour guides. On the other hand, the level of work exhaustion and emotional intelligence are important matter closely related to the implementation of qualified hospitality activity.

Based on the narration, this research intends to investigate whether (1) psychological empowerment significantly affects work exhaustion, (2) psychological empowerment has a significant effect on the emotional intelligence, and (3) work exhaustion has a significant effect on the emotional intelligence.

\section{LITERATURE REVIEW}

Psychological Empowerment. Theories that have been stated become the reference of this study because of its proximity to the fact and reality in the tour guide environment. Thomas \& Velthouse (1990) and Spreitzer (1995) report that psychological empowerment is understood as multi-dimensional construct consisting of four indicators: meaning, competence, self-determination, and impact. If all four indicators are incorporated, they will form the overall construct of psychological empowerment, or in other words, if one of the indicators does not exist, the psychological empowerment will not reach its maximum capacity. Furthermore, Spreitzer (1996) describes empowerment as a way of looking at themselves in the work environment and the extent to which someone is able to form his or her work role. Jenskins (1996) argues that the importance of empowerment enables people to do things they previously could not do, including the ability to overcome work exhaustion. Empowerment enables tour guides to grow their confidence to be able to handle problems, either issue relating to the patient or relating to the organization or surrounding community. Brancato (2003) argues that the improvement on the empowerment can decrease the work exhaustion experienced in the workplace. The reason is that empowerment enables people to actively utilize their skills, knowledge, and capability.

Empowerment is also understood as a multidimensional construct consisting of four cognitions in which these cognitions reflect how the individual's orientation on his or her work. These four cognitions are meaning, competence, self-determination, and impact. Meaning is a value of an object for the individual, competence means the individual belief on his ability to fulfil the work demand, self-determination means autonomy or control over the behavioural processes in his or work, impact means the degree to which an individual able to influence the result created by his work (Spreitzer, 1996). In summary, empowerment is the degree to which an individual can actively influence the work role and work context (Daniels and Guppy 1994).

Work Exhaustion. Bhanugopan \& Alan (2006) said that workers who have experienced work exhaustion would also experience mental exhaustion, loss of commitment, emotional exhaustion, and also decreased motivation over time. Baron \& Greenberg (2008) state that work exhaustion has four indicators consisting of physical exhaustion, emotional exhaustion, and mental exhaustion as well as lack of self-appreciation. Physical exhaustion is lack of energy in a person by feeling exhausted in a long period of time and show physical complaints such as a headache, nausea, insomnia, and changes in appetite expressed with less passionate in his or her work, more mistakes are made, feel the pain even when there is no physical abnormality (Baron \& Greenberg 2008). Emotional exhaustion is an indicator of the condition of work exhaustion in the form of emotion as a result of excessive 
psychoemotional demands marked by loss of feeling and attention, trust, interest, and enthusiasm (Pines \& Aronson, 1989). Someone who experiences certain mental exhaustion will feel empty, tired and can no longer overcome the demands of his or her job. The lack of self-esteem is an indicator of the lack of self-actualization, lack of work motivation and the decreased of self-confidence. This condition is often seen in a tendency of low achievement of the worker (Cordes \& Dougherty, 1993; dan Maslach, 2001).

Maslach (1982) implicitly acknowledges the existence of factors supporting the creation of work exhaustion in the workplace where interaction between the provider and recipient of the service are causing the physical exhaustion. In addition, the analysis is required in order to assess individual factors in the service provider who has contributed to the occurrence of work exhaustion. Thus, the occurrence of work exhaustion is not solely due to stress but also by the presence of individual characteristics, work environment, and emotional involvement with the recipient of service.

Emotional Intelligence. After being published by Goleman back in 1995, emotional intelligence became one of popular topic conversation in the American companies. Goleman (2003) states that emotional intelligence is a capacity in recognizing the emotions of oneself and others, in motivating oneself and managing our own emotion well or in the relationship with the environment. Goleman (2003) states more explicitly that emotional intelligence is additional ability owned by someone in self-motivation, resilience in facing the failure, controlling the emotion and delaying the satisfaction as well as managing the soul. Someone will be able to locate his or her own emotion in appropriate portion, having selfsatisfaction and managing her or his own mood through emotional intelligence. Cooper \& Sawaf (2002) define emotional intelligence as the ability to feel, understand, and selectively apply the emotional power and sensitivity as the source of the human energy and influence. Emotional intelligence demands the owner of the feeling to learn how to recognize and appreciate emotion of oneself and others as well as respond appropriately, applying the emotion selectively in the everyday life. Emotional intelligence is not enough by having only the emotion. Sala (2005) states that there are two sides of emotional intelligence namely the intelligence of understanding the emotion and adding the creativity and intuition in the logical mind.

According to Goleman (2003), emotional intelligence can be defined as selfawareness, self-confidence, self-mastery, commitment, and integrity of a person, and one's ability to communicate, influence, initiate change and accept it. On other words, Goleman (2000) explains that emotional intelligence is divided into five main areas, namely the ability to recognize self-emotion, manage the self-emotion, motivate oneself, recognize other people emotion, and the ability to build a relationship with other people. Mayer and Salovey (2004), state that emotional intelligence is the individual ability in using his or her emotion effectively to manage and influence the relationship with other people.

Hypotheses:

$\mathrm{H}_{1}$ : Psychological empowerment has a significant effect on the work exhaustion;

$\mathrm{H}_{2}$ : Psychological empowerment has a significant effect on the emotional intelligence;

$\mathrm{H}_{3}$ : Work exhaustion has a significant effect on the emotional intelligence.

\section{METHODS OF RESEARCH}

The type of this research is explanatory research which explains the reciprocal relationship between independent variable and dependent variable through hypothesis testing that has been formulated previously. Nusa Tenggara Barat (NTB) Province is chosen as a research location because it is one of promising tourism destinations in Indonesia.

The population in this research are 563 tour guides in NTB province who have attended the standard competence of tourist guide with a license. The sample in this research is 150 tour guides determined using Stratified Proportionate random sampling, considering that the members of the population in this research are stratified.

The questionnaire is used as a data gathering tool, and its measurement scale uses the Likert scale because it can be used to measure attitude, opinion, and perception of 
individual or group of people regarding the social phenomenon. The method of data analysis in this study uses two analyses namely descriptive analysis with the help of SPSS version 20.0. The descriptive statistical analysis is used to provide a description of the frequency, percentage, and average values that have been collected from the questionnaire distribution. The result of the descriptive analysis is very useful to support the interpretation of the result of other analysis methods. After that, using the inferential analysis with Generalized Structured Component Analysis (GSCA). GSCA is used because the researcher can conduct three activities simultaneously, namely the validity and reliability testing of the instrument or equivalent with the confirmatory factor analysis, the relationship model testing between latent variables or equivalent with the analysis path as well as obtaining the useful model to predict or equivalent with the regression analysis model.

\section{RESULTS AND DISCUSSION}

Descriptive Analysis. Description of respondents in this study is grouped by gender, age, education level, marital status, license qualification level, work option status, and work period. The results of the description can be seen in Table 1.

Table 1 - Respondents description by gender, age, education level, marital status, license qualification level, work option status, and work period

\begin{tabular}{llll}
\hline No & Respondents Description & Frequency & Percentage \\
\hline 1 & Gender - male & 144 & 95.30 \\
2 & Age -- >43-47 years old & 35 & 23.33 \\
3 & Education level - Senior High School & 106 & 70.70 \\
4 & Marital Status -- Married & 103 & 68.70 \\
5 & License qualification level -- Young & 98 & 65.30 \\
6 & Preferred work status -- freelance & 137 & 91.30 \\
7 & Work period -- >15 years & 53 & 35.33 \\
\hline
\end{tabular}

There are four indicators used in forming the psychological empowerment variables in this study, among other: meaning, competence, self-determination, and impact. Meaning indicator ranks first in obtaining the average value, namely 4.53 because most of the respondents are strongly agree in responding the indicator. The respondents believe that what they feel is very appropriate for the real situation. The competency indicator ranks on the second place because it only has the average value of 4.50 , this happens because respondents also strongly agree in responding the indicator. The impact indicator ranks on the third place because the respondents perceive it with an average value of 4.47 . In the last sequence is the self-determination indicator responded by the respondents with an average value of 4.38 . The average score of the four indicators in this psychological empowerment variable is based on the interpretation of values in a very high category. However, in order to obtain overall psychological empowerment, it is expected to increase self-determination.

Four indicators are used to form the work exhaustion variable. These four indicators are physical exhaustion, emotional exhaustion, depersonalization, and decreased personal achievement. The highest average value of depersonalization indicator is 4.05 because most of the respondents state that they strongly disagree. Decreased personal achievement indicator is in the second place because it is perceived not in accordance with the circumstance experienced by the respondents. Thus, it is perceived by the respondents with the average value of 4.02. Emotional exhaustion indicator ranks in the third place because it is perceived by the respondents with the average value of 3.85. Physical exhaustion ranks in the fourth place because it is perceived lower comparing to other indicators with the average value of 3.79. This indicates that the last two indicators are perceived by the respondents in which as many as $14.00 \%$ respondents are hesitant, as many as $19.33 \%$ respondents agree, as many as $0.67 \%$ strongly agree. However, the average value of these two indicators is in the higher category if being interpreted. In order to reduce the work exhaustion, it is better to pay more attention to the circumstance of physical exhaustion and emotional exhaustion. 
Five indicators used in order to form emotional intelligence variable, among others: self-awareness, self-regulation, self-motivation, empathy, and social skills. Self-motivation indicator is an indicator responded by the respondents with the highest average value of 4.42 because the respondents strongly agree that this indicator is similar to the condition they have experienced. The second order is occupied by self-regulatory indicator and social skills indicator that have the same average value of 4.39 because most respondents stated that they strongly agree, because the self-regulation and social skills are similar to the condition they have experienced. Self-awareness ranks in the third order because this indicator is responded by the respondents with an average value of 4.38 . Furthermore, the last order is empathy indicator which is perceived lower than the four indicators used to form emotional intelligence variable with an average value of 4.34 , because as much as $16.67 \%$ gave the choice of answers with hesitation. Thus, in order to obtain a complete emotional intelligence, it is expected that they have to increase the empathy.

Inferential Analysis. Before testing the influence between exogenous variables with endogenous variables using GSCA, it is necessary to do linearity assumption test. The linearity assumption test aims to know whether two variables have the linear relationship or not. If the result of assumption test is linear, it can be said that the testing using GSCA can be continued. Linearity relationship has a meaning that there is a direct relationship between exogenous variable and endogenous variable. It can be proven by comparing the significance level with 0.05 . If the value of significance level $<0.05$, then the relationship is linear, but if the value of significant level> 0.05, then it is not linear. Based on the linearity test result conducted in this study on the existing variables, the researcher obtained a significant level of relationship between psychological empowerment variable and work exhaustion in the testing result. The significant linear model is $0.000<0.05$ and the value of significant level of the relationship between psychological empowerment variable and emotional intelligence variable from the test result is a significant linear model of $0.000<0.0$ and the value of significant level of relationship between work exhaustion variable and emotional intelligence variable is significant linear model of $0.000<0.05$.

Assessment of the latent variable measurement model in this study is conducted with GSCA with three criteria namely Convergent Validity, Discriminant Validity, and Composite Reliability. Based on the three criteria of measurement model assessment from the bootstrapping result using GSCA method, and the result of measurement model test against each item of a statement contained in each indicator reflects the latent variable. Assessment of psychological empowerment variable measurement model consists of four indicators with two items statement in each indicator. The meaning indicator consists of statement items, employment significance, and commitment to the profession. Competence indicator consists of statement items, capability in guiding and creating the profession quality. The selfdetermination indicator consists of statement items, problem-solving and the determining the ultimate compensation. The last one is impact indicator consists of statement items that affect the organization development and organization regulation. The root value of Average Variance Extracted (AVE) in the psychological empowerment variable is 0.513 . The value of $\mathrm{AVE}=0.513>0.50$ which means that the instrument used in order to measure the latent variable regarding the psychological empowerment has good discriminant validity. Similarly, the value of Critical Ratio $(C R)>1.96$ results indicates that the instruments used to measure psychological empowerment variable has appropriate composite reliability. In addition, the amount of value of estimate in weight obtained for each item. The point of the meaning of work is the item that can describe the psychological empowerment because the weight estimate value in the item is the largest among the eight existing items, which is equal to 0.238 . Based on the critical point value obtained, the meaning of the work gives a significant influence on psychological empowerment variable because the critical point value obtained is $10.17^{*}$ at $95 \%$ confidence level. The alpha value generated on the psychological empowerment variable is equal to 0.861 . If the value of Alpha $=0.861>0.60$ then all of the items contained in the psychological empowerment has met the criteria Composite reliability because it has a high compatibility, and reliability. 
Based on the measurement scale used to measure the overall item in the psychological empowerment variable, which is the range of the scale starts from one to five which means very bad to very good. The average score of the overall items in the psychological empowerment variable is obtained based on this measurement scale. Observing the actual condition based on the questionnaire result, the average score on each item above is 4.20 including the highest category compliance with the circumstance experienced by the respondents. The overall existing indicators should be maintained because all of them are very good to be used to measure the psychological empowerment variable. Furthermore, for the assessment of structural model and hypothesis testing, from the eight items on the psychological empowerment variable, the researcher chose few items that will represent the indicators. The items are chosen based on the largest weight estimate value owned. In this case, there are four items used to assess the structural model and hypothesis testing namely the item about the meaning of work, capability in guiding, problemsolving, and influencing the development of the organization.

Assessment of work exhaustion variable measurement model consists of four indicators with two items statement in each indicator. The indicator of physical exhaustion consists of the statement of physically helpless, and the decreased of work enthusiasm. The emotional exhaustion consists of the psychologically helpless statement and the boredom of working. The depersonalization indicator consists of the ignorant statement, and not caring about the interest of others. The indicator of the personal achievement decline consists of the statement of inability to solve the problem and to be awarded. The Average Variance Extracted (AVE) root value of 0.618 . The AVE value $=0.618>0.50$ means that the instrument used to measure the latent variable regarding work exhaustion has good discriminant validity. Similarly, the result of Critical Ratio (CR) value $>1.96$ this shows that the instrument used in order to measure the work exhaustion variable has appropriate composite reliability. Furthermore, the amount of the estimated value of the weight is obtained for each item of the statement. The responded statement item least appropriate with the respondents' circumstance is not caring about the interest of other. Thus, this item can describe work exhaustion better because the value of weight estimate in the item is the largest compared to the other eight existing items amounted to 0.231. Similarly, the value of critical point obtained, not caring on the interest of others gives the significant influence on the work exhaustion variable because the value of critical point obtained amounted to $13.33^{*}$ is significant at the $95 \%$ confidence level. Alpha values generated on work exhaustion variable on work exhaustion variable has met the Composite reliability criteria, due to their high compatibility and reliability.

The measurement used to measure the overall items in the emotional intelligence variable which is the range of the scale starts from one to five which means very bad to very good. It is found that the average score of the overall indicator is above 4.20 in the very high category for the incompatibility with the situation experienced by the respondents. The overall existing indicators should be maintained because all of them are very good to be used to measure the emotional intelligence variable. Furthermore, for the assessment of structural model and hypothesis testing, from the tenth items on the emotional intelligence variable, the researcher chose few items that will represent the indicators. The items are chosen based on the largest weight estimate value owned. In this case, there are four items used to assess the structural model and hypothesis testing namely the item about deciding what to do, express the emotion appropriately, enthusiasm to achieve better, understand other people in facing the issue and communicate well with a related institution.

The overall model testing in this research uses goodness-of-fit criteria from GSCA, resulting in the value of fit mode: structural and overall model seen from the value of FIT, AFIT, GFI, and SRMR. Based on the data processing using GSCA the result can be seen in Table 2.

Based on the data in Table 2 about the Evaluation of Goodness-of-fit Model: Structural and Overall Model, it can be explained that FIT is a total variant of the overall analyzed variables. The value of FIT in the data processing has the value amounted to 0.562 which means that the model formed in this research can describe all of the analyzed variables as 
many as $56.20 \%$. The diversity of the psychological empowerment, work exhaustion, emotional intelligence can be explained by the model as many as $56.20 \%$ while the remaining $43.80 \%$ is explained by another variable outside the model of this research. Considering that the value of FIT amounted to $56.20 \%$ it can be concluded that the model in this study has a fairly good model accuracy.

Table 2 - Evaluation of Goodness-of-fit Model: Structural and Overall Model

\begin{tabular}{ccc}
\hline No & Fit Model & Fit Value \\
\hline 1 & FIT & 0.562 \\
2 & AFIT & 0.554 \\
3 & GFI & 0.990 \\
4 & SRMR & 0.090 \\
\hline
\end{tabular}

Furthermore, AFIT (Adjusted FIT) is similar to $\mathrm{R}^{2}$ adjusted in the regression analysis. The value of AFIT amounted to 0.554 is the adjusted of FIT similar to the value of FIT. The value of AFIT amounted to 0.554 means that the model formed in this research can be explained by all of the analyzed variables as many as $55.40 \%$. The diversity of the psychological empowerment, work exhaustion, emotional intelligence can be explained by the model as many as $55.40 \%$ while the remaining $44.60 \%$ is explained by another variable outside the model of this research. Considering that the value of AFIT is larger than $50 \%$ it can be concluded that the model in this study has a fairly good model accuracy. Both GFI and SRMR are proportional to the difference between the sample covariance produced by the GSCA parameter estimation. The value of GFI amounted to $0.990>$ cut-off point 0.90 which means that model formed in this research is said to be appropriate or good because the value of SRMR is smaller than 0.1 or $0.090<0.1$.

Based on the above description, it can be concluded that the complexity of the model contained in this study is able to explain $56.40 \%$ variance data that has been corrected, and it also shows appropriate or good fit model indicated by GFI $=0.990$ and $\mathrm{SRMR}=0.090$ which is close to the value of 0 .

Based on testing of structural model and hypothesis on the basis of the estimated value of path coefficient regarding the direct influence between the variable of psychological empowerment to work exhaustion variable. 2) Testing of structural model and hypothesis on the basis of estimation of path coefficient about direct influence of the psychological empowerment variable to emotional intelligence variable, and 3) Testing of structural model and hypothesis based on estimation value of path coefficient about direct influence of work exhaustion variable to emotional intelligence variable. Test results can be seen in Table 3.

Table 3 - Path Coefficient of Direct Effect and Hypothesis Testing

\begin{tabular}{|c|c|c|c|c|c|}
\hline \multirow{2}{*}{ Hypothesis } & \multirow{2}{*}{ Relationships Between Variables } & \multicolumn{3}{|c|}{ Path Coefficients } & \multirow[b]{2}{*}{ Description } \\
\hline & & Estimate & SE & CR & \\
\hline $\mathrm{H}_{1}$ & \multirow{2}{*}{$\begin{array}{c}\text { Psychological Empowerment } \rightarrow \text { Work Exhaustion } \\
\text { Psychological Empowerment } \rightarrow \text { Emotional } \\
\text { Intelligence }\end{array}$} & -0.270 & 0.087 & 3.10 & Significant \\
\hline $\mathrm{H}_{2}$ & & 0.460 & 0.068 & $6.73^{*}$ & Significant \\
\hline $\mathrm{H}_{3}$ & Work Exhaustion $\rightarrow$ Emotional Intelligence & -0.030 & 0.072 & $0.41^{*}$ & $\begin{array}{l}\text { Non- } \\
\text { significant }\end{array}$ \\
\hline
\end{tabular}

Table 3 provides an overview of the direct path coefficient estimation value of each research variable, such as the relationship of psychological empowerment with work exhaustion, and the relationship of psychological empowerment with emotional intelligence, as well as the relationship of work exhaustion with the emotional intelligence. For the purpose of testing the research hypothesis, we use the value of Critical Ratio (CR) in which the results obtained by processing through GSCA.

The discussion regarding the influence of psychological empowerment on the work exhaustion is the answer of the problem formulation and hypothesis of the second research $\left(\mathrm{H}_{1}\right)$ which states that the psychological empowerment has a significant influence on the work exhaustion. The result of analysis on structural model with GSCA method shows that 
psychological empowerment has significant and negative effect on work exhaustion, based on the result of data in Table 2, the estimated value of the path coefficient of -0.270 with negative direction, and critical point value (CR) equal to $3.10^{*}$ at the confidence level of $95 \%$. This means that the higher the level of psychological empowerment experienced by the respondents, the lower the work exhaustion will be experienced by the respondents.

The finding from the empirical study shows that the perception of the respondents on the psychological empowerment variable, mainly the meaning indicator, and the competence indicator have a very high value because the scores of the two indicators are mostly rated with the score 4 , and score 5 so that the value of average score of meaning indicator amounted to 4.53 and competence indicator amounted to 4.47 which is above or equal to the average value of the score from the overall indicators in the psychological empowerment variable amounted to 4.37 . This indicates that the respondents realistically feel the value of meaning of the tour guide profession in his or her life, and they also feel that the competence owned greatly support the activity of serving the guests.

This study found that the influence of psychological empowerment inversely proportional to work exhaustion, namely the higher the level of psychological empowerment felt by the respondents, the lower the level of work exhaustion they have experienced. This can happen because the results of a descriptive study in this research show that most of the people who have decided to do this tour guide profession are mostly male amounted to $95.30 \%$ and the remaining percentage is women amounted to $4.70 \%$. It is known that the tour guide profession has a specific characteristic such as unique, dynamic, and challenging. Thus, it requires physical endurance and mental strength. Men usually have a stronger physical endurance than women. On the other hand, men prefer to use logical thinking rather than emotion. This indicates that men will able to control work exhaustion he has to experience.

The second reason can be explained by the result of a descriptive study in this research. The age of the respondents are mostly above 43-47 years old amounted to $23.33 \%$. The age of development is called as middle age by Santrock (2003) because at this age phase people will have mental, emotional, social and very productive maturity. It means that people at the age above 43-47 years old will be able to manage the job he is pursuing seriously with a strategic method in order to decrease the work exhaustion he has to experience. The third reason is based on the result of a descriptive study in this research, regarding the work period of the respondents, respondents who have worked for 15 years amounted to $28.70 \%$, and generally, the respondents with this work period have broad insight, skilful and experienced in providing the service. This shows that a tour guide with rich experience, adequate skills, and broad insight will certainly know how to overcome the level of work exhaustion he or she has to experience. The fourth reason, when observing from the marriage status of respondents most of them are married which amounted to $68.70 \%$. People who have been married are generally not too concerned about the work exhaustion he has to experience because psychologically speaking he has a family that becomes his responsibility. Thus, he will be more focused and serious in carrying out the work in order to obtain adequate income and to support his children and wife.

Based on the description, the result of this research is different than the theory conveyed by Schaufeli, Maslach \& Marek (1993) concerning the excessive workload that can be one of the factors for work exhaustion. The result of this research is also different with the Santrock (2003) theory, he states that if someone is assigned to excessive work continuously, it will cause a burnout for the assigned person due to the overload emotion of the physical and mental exhaustion which is also the accumulation of stress in a long period of time. However, the research result confirms and expands the research result conducted by Yagil (2006) concerning "The relationship of service provider power motivation, empowerment, and burnout to customer satisfaction". The research result conducted by Yagil shows that empowerment is negatively correlated with burnout, including emotional exhaustion, depersonalization, and decreased personal achievement, meaning that the higher the perceived empowerment, the lower the burnout will be. 
This research result also confirms and expands the finding of research conducted by Alam (2010), in which Alam finds that the empowerment has no significant influence on the work exhaustion. It means that even if the respondents in the research feel empowered, but she or he cannot increase or decrease the exhaustion directly. However, this research result can be different comparing to the research result conducted by Greco, et al. (2006) on Leader empowerment behaviors, staff nurse empowerment and work engagement/burnout in Ontario Canada. The finding of the Greco, et al. (2006) research shows that empowerment has a positive influence on the involvement, and it has a significant positive effect on work exhaustion.

The discussion regarding the influence of psychological empowerment on the emotional intelligence is the answer of the problem formulation and hypothesis of the third research $\left(\mathrm{H}_{2}\right)$ which states that the psychological empowerment has a significant influence on the emotional intelligence. The result of analysis on structural model with GSCA method shows that psychological empowerment has significant and positive effect on emotional intelligence, based on the result of data in Table 3, the estimated value of the path coefficient of 0.460 with positive direction, and critical point value (CR) equal to $6.73^{*}$ at the confidence level of $95 \%$. This means that the higher the level of psychological empowerment experienced by the respondents, the higher the emotional intelligence that will be experienced by the respondents or tour guides in NTB province.

This study shows that psychological empowerment can run optimally according to the expectations of the tour guides in NTB province, because the overall indicators from the description of the psychological empowerment variables based on the statement points in the overall existed indicators are perceived with strongly agree (score 5) by the respondents, especially on the meaning and competence indicator that have the value of average score of 4.53 and 4.50 respectively. The average score value above the overall average score value in the psychological empowerment variable is 4.47 , and for the emotional intelligence variable based on the existing variable, are perceived very high by the respondents, especially in the self-motivation indicator with the average score value of 4.42 which is above the overall average score value of 4.37. This indicates that the higher the meaning in the work or profession perceived by respondents or tour guides in NTB province, the higher the self-motivation to do the guiding task well. Similarly, the higher the competence level of a tour guide in NTB province, the higher the achievement level they will achieve, and the higher the creativity in creating a pleasant atmosphere to provide quality services.

Based on this, this research result confirms and expands the theory stated by Goleman (2003), on emotional intelligence as the additional ability owned by someone in selfmotivation, resilience in facing the failure, controlling the emotion and delaying the satisfaction as well as managing the soul. Thus, the results of this study accept the theory of Jenskins (1996) which says that the importance of empowerment enables people to do things they previously could not do, including the ability in recognizing self-emotion, managing self-emotion, motivating oneself, recognizing the emotion of other, and the ability to be able to foster the influence with others which is called as emotional intelligence. The results of this study confirm and broaden the findings of Alam (2010) which examines preposition test of the effect of psychological empowerment on the emotional intelligence. Alam (2010) has successfully proved that psychological empowerment has significant positive influence on the emotional intelligence.

The discussion on the influence of work exhaustion on the emotional intelligence is the answer of the problem formulation and hypothesis of the tenth research $\left(\mathrm{H}_{4}\right)$ which states that the work exhaustion has a significant influence on the emotional intelligence. The result of analysis on structural model with GSCA method shows that work exhaustion does not have significant and negative effect on the emotional intelligence, based on the result of data in Table 3, the estimated value of the path coefficient of -0.030 with negative direction, and critical point value (CR) equal to 0.41 at the confidence level of $95 \%$. This indicates that a negative and insignificant effect. This means that there is an inverse effect between work exhaustion and emotional intelligence, if the higher the level of work exhaustion felt by respondents or tour guides in NTB province, the lower the level of emotional intelligence they 
have. But this effect is not significant because it is not supported by the reality that occurs in this research object.

Work exhaustion variable is not significant and negative to the emotional intelligence and it can be explained as follows. First, based on the data in the field of work fatigue experienced by the respondents or guides in the province of NTB is generally categorized as low, because the majority of items contained in work exhaustion are responded with strongly disagree, because it is not in accordance with the conditions experienced by the respondents, except in physical fatigue indicator, and emotional exhaustion, some of the respondents perceive it as high because they feel the compatibility with the condition they are experiencing. This can happen because tour guide is non-scheduled work and it is different than full-time work started at 7 and finish at $5 \mathrm{pm}$. Tour guides working hour may be longer and it can be extended more than 24 hours a day. Sometimes, they have to serve guests at $3 \mathrm{AM}$, and they are also often required to respond immediately. They are demanded to solve or find a solution for an issue. Things like this can trigger work exhaustion of a tourist guide, primarily in exhaustion of energy. Babakus et al. (1999) state that work exhaustion can be defined as running out of energy. Bhanugopan, et al. (2006) suggest that work exhaustion in which its occurrence is responded very well because it happens when a person tries to achieve an unrealistic goal, eventually he runs out of energy and loses the feeling about himself, and against others.

The results of the test in this study found that the high or low work exhaustion experienced by the tour guides in the province of NTB, the influence cannot increase or reduce the high or low of the emotional intelligence. It can happen because the respondents' adaptation to their current work has been going on for a very long time, the majority of respondents have worked as a tour guide for more than 15 years. It means that the respondents have understood very well the characteristics of their work in which they have to interact with a lot of people. And that this work requires him to have easy going personality, no matter how complicated and talkative the guest they have to serve. An individual with a passionate soul, positive thinking, energetic, open, attractive, has a sense of purposeful humour, cheerful, and also has good communication skills, as well can entertain others, is a person who has emotional maturity. According to Walgito (2002), people who have emotional maturity can place himself in tune with the realities he has to face the environment. Furthermore, Patton (1998) argues that emotional maturity is the ability to control emotions effectively to achieve goals and build a productive influence in order to achieve success.

Second, the test results in this study found that the high or low of work exhaustion experienced by the tour guides in the province of NTB, its influence cannot increase or reduce the high or low of the emotional intelligence. This happens, because the tour guides in NTB province are aware of the heavy demands and challenges in carrying out their work as tour guides. However, most of them have done this work more than 15 years, it means that they are very experienced in fulfilling the demands and solving the problems. Robbins (2006) argues that someone's working experience in the work he has manifested in the number of work period can improve the ability, and work skills of that person which will generate the improved work. Work experience is not only about the number of work period, but more than taking into account the type of work that he has done or often faced (Asri, 1986).

Based on the interview with one of tour guides in NTB province, a tour guide named Mr. Mulyadi, on March 23, 2014, revealed that he can act decisively, quickly and appropriately in solving an issue, able to control his emotion when facing the issue, and being careful or cautious all the time, as well as anticipating every issue that has not arrived yet due to his experience as tour guide and his natural instinct. Such professional and ethical attitude and behavior can cultivate a reliable work culture because it is instilled continuously on himself and other people in order to produce an identity and a good image for tour guides in the province of NTB.

This kind of work culture serves as guidance in carrying out duty to serve the guest. Ndraha (2003) states that the culture is a social behavior and phenomenon that can give the picture of the identity and image of individual or group because everyone's culture is different 
from others, and ansich culture cannot be defined as good or bad because everyone and every group has their own culture. Luthan (2006) states that work culture can be defined as the knowledge obtained to integrate the experience and create social behavior. If the work culture can be implemented appropriately and properly, then the behavior of human resources in achieving the work productivity will be higher (Djajendra, 2013).

This research result is different from Bhanugopan \& Alan's Theory (2006) regarding the workers who are experiencing burnout will also experience mental exhaustion, loss of commitment, emotional exhaustion, and decreased self-motivation over time. Goleman (2000) states that self-motivation is also part of emotional intelligence. Similarly, the research result is not in line with the research result conducted by Thomas, et al. (2012). Their research result found a significant positive effect between emotional exhaustion and emotional exhaustion. Furthermore, there is also significant positive effect between depersonalization and emotional intelligence. There is also a positive significant influence between personal achievement and emotional intelligence. Based on that, Thomas, et al. (2012) give a conclusion that work exhaustion has a positive significant effect on emotional intelligence.

\section{CONCLUSION}

Based on the problem formulation, research result, and discussion, it can be concluded that psychological empowerment has a direct negative significant influence on the work exhaustion. Psychological empowerment has a significant positive effect on emotional intelligence, and work exhaustion has no significant negative effect on the emotional intelligence.

Basically, every research always has a limitation, not to mention this research. The reason is that this research is part of explanatory research using cross-sectional study approach in which the researcher cannot follow the behaviour of the subject or respondent from time to time in gathering the data of the research. It greatly affects the result of the analysis.

\section{REFERENCES}

1. Alam, R. 2010. Pengaruh Pemberdayaan Terhadap Kelelahan Kerja dan Kecerdasan Emosional Perawat dan Bidan Pada Rumah Sakit Umum Rujukan di Sulawesi Selatan. Jurnal EKUITAS, pp.187-209.

2. Asri, M. 1986. Pengelolaan Karyawan. Yogyakarta: BPFE.

3. Babakus, E., Cravens D.W., Johnston M., \& Moncrief, W.C. 1999. The Role of Emotional Exhaustion in Sales Force Attitude and Behavior Relationships. Journal of the Academy of Marketing Science. Vol.27. No.1, pp.58-70.

4. Baron, R.A. \& Greenberg, J. 2008. Behaviour in organization: understanding and managing the human side of work. 9th ed. USA: Prentice Hall.

5. Bhanugopan, R. \& Alan, F. 2006. An Empirical Investigation of Job Burnout among Expatriates. Personal Review, Vol.35. No.4, pp.449-468.

6. Brancato, V. 2003. Enhancing Psychological Empowerment for nurses. Pensylvania Nurse. Vol. 50, pp. 10-11.

7. Chow, W-C., Lo, S., \& Hong, J. 2005. The Impact of Developmental Experience, Empowerment, and Organizational Support on Catering Service Staff Performance. Hospitality Management, Vol. 25. No. 3, pp. 478-495.

8. Conger, J.A. \& Kanungo, R.N. 1988. The empowerment process: Integrating theory and practice. Academy of Management Journal, Vol.13. No.3, pp.471-482.

9. Cooper, R.D. \& Sawaf, A. 2002. Executive EQ: Emotional Intelligence in Business. London: Orion.

10. Cordes, C.L. \& Dougherty, T.W. 1993. A Review and Integration of Research on Job Burnout. Academy of Management Review. Vol.18, pp.621-656. 
11. Daniels, K. \& Guppy, A. 1994. Occupational Stress, Social Support, Job Control and Psychological Well-Being. Human Relation, Vol 47, pp. 1523-1538.

12. Goleman, D. 1995. Emotional intelligence: Why it can matter more than IQ. NY: Bantam.

13. Goleman, D. 2000. Emotional Intelligence (Kecerdasan Emosional). Translated by T. Heryana. Jakarta: Gramedia Pustaka Umum.

14. Goleman, D. 2003. Maxed Emotions. Business Strategy Review, Vol.14. No.2, pp.26-32.

15. Greco, P., Keather, K., Laschinger, S., \& Carol, W. 2006. Leader Empowering Behaviours, Staff Nurse Empowerment and Work Engagement/Burnout. Nursing Leadership, Vol.19. No.4, pp.56-67.

16. "Hampir 50 Persen Pramuwisata NTB Tidak Berlisensi". 2012. Retrieved from http://www. antaranews.com on October 24th, 2013.

17. Kong, H., Cheung, C., \& Baum, T. 2009. Are Tour Guides in China Ready for the Booming Tourism Industry?. Journal of China Tourism Research, Vol.5, pp.65-76.

18. Maslach, C. 1982. Burnout. The cost of coring. NJ: Prentice-Hall.

19. Maslach, C. 2001. Annual Review of Psychology: Job Burnout. Retrieved from http://www.Annual-reviews.org /maslach_01 on October 2nd, 2011.

20. Mayer, J.D. \& Salovey, P. 1990. Emotional Intelligence. Imagination, Cognition, and Personality, Vol.9. No.3, pp.185-211.

21. Meyer, J.P., Becker, T.E., \& Vandenberghe, C. 2004. Employee commitment and motivation: A conceptual analysis and integrative model. Journal of Applied Psychology.Vol. 89, pp. 991-1007.

22. Meyerson, G. \& Dewettinck, B. 2012. Effect of Empowerment on Employees Performance. Advanced Research in Economic and Management Sciences. Vol.2, pp. 40-46.

23. Ndraha, T. 2003. Budaya Organisasi. Jakarta: Renike Cipta.

24. Santrock, J.W. 2003. Psychology Essentials. Boston: McGraw-Hill.

25. Sala, F. 2005. Making connections: The link between emotional intelligence and sales performance. Australian Institute of Training Development, Vol.32, pp.1-25.

26. Patton, P. 1998. Kecerdasan Emosional di Tempat Kerja. Translated by Z. Dahlan. Jakarta: Pustaka Delaprata.

27. Pines, A. \& Aronson, E. 1989. Burnout: From tedium to personal growth. NY: The Free Press.

28. Robbins, S. 2006. Organizational Behavior (10th Edition). Translated by B. Molan. Jakarta: Macan Jaya Cemerlang.

29. Sarwar, A. \& Khalid, A. 2011. Impact of Employee Empowerment on Employee's Job Satis-faction and Commitment with the Organization. Interdisciplinary Journal of Contemporary Research In Business, Vol.3. No.2, pp.664-683.

30. Schaufeli, W.B., Maslach, C., \& Marek, T. 1993. Profesional Burnout: Recent Developments In Theory and Research. Journal of Happiness Studies, Vol. 3, pp.71-92.

31. Spreitzer, G.M. 1995. Psychological empowerment in the workplace: dimen-sions, measurement, and validation. Academy of Management Journal. Vol.38. No.5, pp.14421465.

32. Spreitzer, G.M. 1996. Social Structural Characteristics of Psychological Empowerment. Academy of Management Journal, Vol. 39. No. 2, 484-504.

33. Thomas, K.W. \& Velthouse, B.A. 1990. Cognitive elements of empo-werment: An Interpretive model of intrinsic task motivation. Academy of Management Review, Vol.15. No.4, pp.666 -681.

34. Thomas, N.S. Mousavy, S., Mukundan, J., \& Nimeh-Chisalem, V. 2012. The Relationship between Burnout and Trait Emotional Intelligence among Secondary School Teachers in Malaysia. International Journal of Applied Linguistics \& English Literature, 1. No.4, pp.1523.

35. Tutar, H., Altinoz, M., \& Cakiroglu, D. 2010. The Effects of Employee Empowerment on Achievement Motivation and the Contextual Performance of Employees. African Journal of Business Management, Vol. 5. No.15, pp. 6318-6329. 
36. Vucetic, A. 2012. Human Resources as a Competitive Advantage of Travel Agencies in Montenegro. Journal TURIZAM, Vol.16. No.2, pp. 78-87.

37. Yagil, D. 2006. The Relationship of Service Provider Power Motivation, Empowerment and Burnout to Customer Satisfaction. International Journal of Service Industry Management, Vol.17.No.3, pp. 258-270. 